\title{
Synthesis and Electrocatalytic Oxygen Reduction Properties of Truncated Octahedral $\mathrm{Pt}_{3} \mathrm{Ni}$ Nanoparticles
}

\author{
Jianbo Wu and Hong Yang ( $\square)$ \\ Department of Chemical Engineering, University of Rochester, Gavett Hall 206, Rochester, New York 14627, USA \\ Received: 11 August 2010 / Revised: 13 September 2010 / Accepted: 18 September 2010 \\ (C) The Author(s) 2010. This article is published with open access at Springerlink.com
}

\begin{abstract}
$\mathrm{Pt}_{3} \mathrm{Ni}$ nanoparticles have been obtained by shape-controlled synthesis and employed as oxygen reduction electrocatalysts for proton exchange membrane fuel cells (PEMFC). The effects of varying the synthesis parameters such as the types of the capping agent and the reducing agent, and the reaction time have been systematically studied. The as-prepared $\mathrm{Pt}_{3} \mathrm{Ni}$ nanoparticles were subjected to a butylamine-based surface treatment in order to prepare carbon-supported electrocatalysts. The $\mathrm{Pt}_{3} \mathrm{Ni}$ electrocatalysts show an areaspecific activity of $0.76 \mathrm{~mA} / \mathrm{cm}^{2}(\mathrm{Pt})$ at $0.9 \mathrm{~V}$ in an alkaline electrolyte, which is 4.5 times that of a commercial $\mathrm{Pt} / \mathrm{C}$ catalyst $\left(0.17 \mathrm{~mA} / \mathrm{cm}^{2}(\mathrm{Pt})\right)$. The mass activity reached $0.30 \mathrm{~A} / \mathrm{mg}(\mathrm{Pt})$ at $0.9 \mathrm{~V}$, which is about twice that of the commercial $\mathrm{Pt} / \mathrm{C}$ catalyst. Our results also show that the area-specific activities of these carbon-supported $\mathrm{Pt}_{3} \mathrm{Ni}$ electrocatalysts depend strongly on the (111) surface fraction, which is consistent with the results of a study based on $\mathrm{Pt}_{3} \mathrm{Ni}$ extended single-crystal surfaces.
\end{abstract}

\section{KEYWORDS}

Pt-based alloy, oxygen reduction reaction, shape control, alkaline solution, truncated octahedron

\section{Introduction}

Fuel cells and batteries offer attractive alternatives to traditional energy conversion systems based on fossil fuels, in terms of efficiency, clean energy production and storage [1-6]. Using oxygen in air as an active ingredient allows these systems to produce energy cost effectively. However, one critical issue to be addressed is the lack of effective Pt-based electrocatalysts for the four-electron reduction of oxygen with a relatively low over-potential [7]. Although $\mathrm{Pt}$ has excellent overall performance for catalyzing the oxygen reduction reaction (ORR), its high cost and limited abundance call for the development of $\mathrm{Pt}$ alloy-based and non-Pt electrocatalysts. Great efforts have been devoted to exploring low-Pt ORR catalysts [2, 8-18], but practical examples of durable [19-21] and highly active [7] catalysts for use in strongly acidic solutions of Nafion-based proton exchange membrane fuel cells (PEMFCs) are still limited. In this regard, the use of alkaline fuel cells could have certain advantages, both in terms of electrocatalytic activity and in materials stability [22-24]. The decreased competitive adsorption by nonreactive anions in alkaline media means that most electrocatalytic steps should be much easier in alkaline solutions than in acidic environments [25]. As a result, ORR catalysts generally exhibit favorable properties in alkaline environments [22, 26, 27].

Recently, compared with conventional Pt/C catalysts,

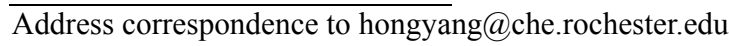


several dozen-fold enhancements in area-specific ORR activity have been achieved by using a vacuumgenerated $\mathrm{Pt}_{3} \mathrm{Ni}$ (111) single crystal surface [8]. This dramatic change in catalytic activity was attributed to both the electronic and surface atomic structures of composition-defined Pt alloys. Thus, control over the shape and composition of $\mathrm{Pt}$ alloy nanoparticles is essential for the development of active catalysts. We recently demonstrated in a communication that a four-fold improvement in ORR activity compared with a $\mathrm{Pt} / \mathrm{C}$ catalyst was possible in an acidic environment by using truncated octahedral $\mathrm{Pt}_{3} \mathrm{Ni}$ electrocatalysts made using solution phase synthesis and a room temperature post-synthesis treatment [11]. In this paper, we present a study of the effects of several key factors affecting the shape control of $\mathrm{Pt}_{3} \mathrm{Ni}$ nanostructures. Carbon-supported $\mathrm{Pt}_{3} \mathrm{Ni}\left(\mathrm{Pt}_{3} \mathrm{Ni} / \mathrm{C}\right)$ catalysts have been prepared and their shapedependent ORR properties in alkaline solution are described.

\section{Experimental}

\subsection{Synthesis of $\mathrm{Pt}_{3} \mathrm{Ni}$ nanoparticles}

The general procedure for preparing the $\mathrm{Pt}_{3} \mathrm{Ni}$ electrocatalysts was similar to that reported elsewhere [11], though detailed studies of the various factors that affect the shape of the particles were carried out in this work.

The synthesis mixture consisted of the following components: (1) borane-tert-butylamine complex (TBAB, Aldrich, 97\%, $100 \mathrm{mg}, 1.14 \mathrm{mmol}$ ); (2) 1-adamantaneacetic acid (AAA, Aldrich, $234 \mathrm{mg}$, $1.2 \mathrm{mmol}$ ), or adamantanecarboxylic acid (ACA, Aldrich, 99\%, $216 \mathrm{mg}, 1.2 \mathrm{mmol}$ ), or $L$-ascorbic acid (Aldrich, $1.2 \mathrm{mmol}$ ); (3) 1,2-hexadecanediol (HDD, Aldrich, 96\%, $1.6 \mathrm{~g}, 6.2 \mathrm{mmol}$ ), or 1,2-dodecanediol (DDD, Aldrich, 90\%, $1.25 \mathrm{~g}, 6.2 \mathrm{mmol}$ ), or 1,2-decanediol (DD, Aldrich, 98\%, $1.08 \mathrm{~g}, 6.2 \mathrm{mmol}$ ); (4) octylamine (Aldrich, $1 \mathrm{~mL}$ ), or dodecylamine (Aldrich, $8.28 \mathrm{mmol}$ ), or hexadecylamine (HDA, TCI, $2 \mathrm{~g}, 8.28 \mathrm{mmol}$ ), or octadecylamine (Aldrich, $8.28 \mathrm{mmol}$ ), or oleylamine $(8.28 \mathrm{mmol})$; and (5) diphenyl ether (DPE, Aldrich, $90 \%, 2 \mathrm{~mL}$ ) which were added to a $25-\mathrm{mL}$ three-neck round-bottle flask under argon flow. Platinum acetylacetonate $\left(\mathrm{Pt}(\mathrm{acac})_{2}\right.$, Strem, 97\%, $\left.0.127 \mathrm{mmol}\right)$ and nickel acetylacetonate $\left(\mathrm{Ni}(\mathrm{acac})_{2}\right.$, Aldrich, $98 \%$, $0.0424 \mathrm{mmol}$ ) were dissolved in $2 \mathrm{~mL}$ of DPE at $60^{\circ} \mathrm{C}$, followed by rapid injection into the above flask. The reaction mixture was maintained at $190^{\circ} \mathrm{C}$ in oil bath for a given time ( $30 \mathrm{~min}, 1 \mathrm{~h}$, or $2 \mathrm{~h}$ ). After the reaction, the product was mixed with $2 \mathrm{~mL}$ of chloroform in a 16-mL plastic vial, followed by the addition of $8 \mathrm{~mL}$ of ethanol. The precipitate was separated from the mixture by centrifugation at $12000 \mathrm{rpm}$ for $5 \mathrm{~min}$. The supernatant was decanted and the black product was dispersed in $2 \mathrm{~mL}$ of chloroform. This separation process was repeated three times. In addition to the above ratio of HDD/TBAB (5.44), a reaction was also carried out with a ratio of 1.36 by using $3.1 \mathrm{mmol}$ HDD and $2.28 \mathrm{mmol} \mathrm{TBAB}$, with HDA as capping agent in the presence of AAA.

\subsection{Preparation of carbon-supported catalysts}

The preparation of carbon-supported $\mathrm{Pt}_{3} \mathrm{Ni}$ catalysts essentially followed the procedure reported elsewhere, but with minor modifications [11]. Vulcan XC-72 carbon was chosen as the carbon support for making $\mathrm{Pt}_{3} \mathrm{Ni} / \mathrm{C}$ catalysts. The carbon particles were dispersed in chloroform and sonicated for $1 \mathrm{~h}$ before the addition of $\mathrm{Pt}_{3} \mathrm{Ni}$ nanoparticles to this dispersion with a nanoparticle:carbon black mass ratio of 1:4. This mixture was stirred overnight and the resulting solid was precipitated by centrifugation and dried under argon.

The solid particles were then re-dispersed in $n$-butylamine (EM, 98\%) at a concentration of $2 \mathrm{mg}$ catalyst $/ \mathrm{mL}$. The mixture was then stirred for 3 days at room temperature, followed by centrifugation at $5000 \mathrm{rpm}$ for $5 \mathrm{~min}$. The precipitate was dispersed again in $10 \mathrm{~mL}$ of methanol and the dispersion was sonicated for $15 \mathrm{~min}$. After mixing well, the supported catalyst was separated from the solution by centrifugation. The same washing procedure was repeated three times. The final samples were dried under an argon flow for further characterization.

\subsection{Electrochemical measurements}

A three-electrode configuration was used to carry out the measurements. A glassy-carbon rotating disk 
electrode (RDE) (area: $0.196 \mathrm{~cm}^{2}$ ) was used as the working electrode, and a platinum foil with the dimensions of $1 \mathrm{~cm} \times 1 \mathrm{~cm}$ as the counter electrode. A reversible hydrogen electrode (RHE, HydroFlex, Gaskatel) was used as the reference and placed in a separate compartment. The electrolyte used for measuring facet-related surface adsorption was $0.5 \mathrm{~mol} / \mathrm{L}$ sulfuric acid $\left(\mathrm{H}_{2} \mathrm{SO}_{4}\right)$. To prepare the working electrode, $2.5 \mathrm{mg}$ of the $\mathrm{Pt}_{3} \mathrm{Ni} / \mathrm{C}$ catalyst was dispersed in $5 \mathrm{~mL}$ of solvent and sonicated for $5 \mathrm{~min}$. The solvent was a mixture of de-ionized water, isopropanol and 5\% Nafion with a volume ratio of 4:1:0.025. $20 \mu \mathrm{L}$ of this ink was added onto the RDE by a pipette and dried in a gentle flow of air. The loading of $\mathrm{Pt}$ on the RDE was calculated to be $9.3 \mu \mathrm{g}(\mathrm{Pt}) / \mathrm{cm}^{2}$. The electrochemical active surface area (ECSA) was determined by integrating the area for the hydrogen adsorption range from cyclic voltammetry (CV) curves under steady state conditions, which were reached after 20 potential cycles at room temperature in argonsaturated $0.1 \mathrm{~mol} / \mathrm{L} \mathrm{KOH}$ solution. The potential scan rate was $50 \mathrm{mV} / \mathrm{s}$. ORR activity was determined based on steady-state polarization curves, which were recorded after 10 sweeps in a $0.1 \mathrm{~mol} / \mathrm{L} \mathrm{KOH}$ solution that was purged with oxygen for $30 \mathrm{~min}$ prior to, and during, the measurements. The scan rate for ORR measurements was set at $10 \mathrm{mV} / \mathrm{s}$ for the positive scan. For comparison, $\mathrm{Pt} / \mathrm{C}$ (TKK, $50 \mathrm{wt} \% \mathrm{Pt}, 3 \mathrm{~nm}$ diameter on Vulcan carbon) was used as the reference catalyst. The loading of $\mathrm{Pt}$ on the RDE was calculated to be $11 \mu \mathrm{g}(\mathrm{Pt}) / \mathrm{cm}^{2}$. The area-specific activity was obtained by normalizing the kinetic current density against the total ECSA, and the kinetic current density was obtained from the Koutecky-Levich plot and normalized against RDE surface area $\left(0.196 \mathrm{~cm}^{2}\right)$.

\subsection{Characterization}

Transmission electron microscopy (TEM) and high-resolution transmission electron microscopy (HRTEM) images were obtained using a FEI TECNAI F-20 field emission microscope (accelerating voltage: $200 \mathrm{kV}$ ). Energy dispersive X-ray (EDX) analysis was carried out on a field emission scanning electron microscope (FE-SEM, Zeiss-Leo DSM982) equipped with an EDX detector. Powder X-ray diffraction
(PXRD) patterns were recorded using a Philips MPD diffractometer with a $\mathrm{Cu} \mathrm{K} \alpha \mathrm{X}$-ray source $(\lambda=$ $1.5405 \AA$ ). The metal composition of $\mathrm{Pt}_{3} \mathrm{Ni} / \mathrm{C}$ catalysts was determined by thermogravimetric analysis (TGA, SDT-Q600, TA Instruments, Inc.). The experiment involved heating the sample to $600{ }^{\circ} \mathrm{C}$ at rate of $10{ }^{\circ} \mathrm{C} / \mathrm{min}$ in flowing air at $50 \mathrm{~mL} / \mathrm{min}$, followed by heating at $600{ }^{\circ} \mathrm{C}$ for $30 \mathrm{~min}$ under a reducing atmosphere of $5 \% \mathrm{H}_{2}$ in $\mathrm{Ar}$ with a flow rate of $50 \mathrm{~mL} / \mathrm{min}$.

\section{Results and discussion}

\subsection{Structure of the $\mathrm{Pt}_{3} \mathrm{Ni}$ nanoparticles}

Figure 1(a) shows a representative TEM image of the sample formed at $190^{\circ} \mathrm{C}$ with a reaction time of $1 \mathrm{~h}$, using $\mathrm{HDA}\left(\mathrm{C}_{16} \mathrm{H}_{33} \mathrm{NH}_{2}\right)$ as capping agent, HDD and $\mathrm{TBAB}$ with a molar ratio of 5.44 as the mixed reducing agents, in the presence of AAA.

The nanoparticles were uniform in overall size and dominated by truncated octahedra (about $90 \%$ in population) with a small population of cubes. The average edge length was around $8.3 \mathrm{~nm} \pm 0.5 \mathrm{~nm}$. The truncated octahedra have a $d$-spacing of $0.22 \mathrm{~nm}$

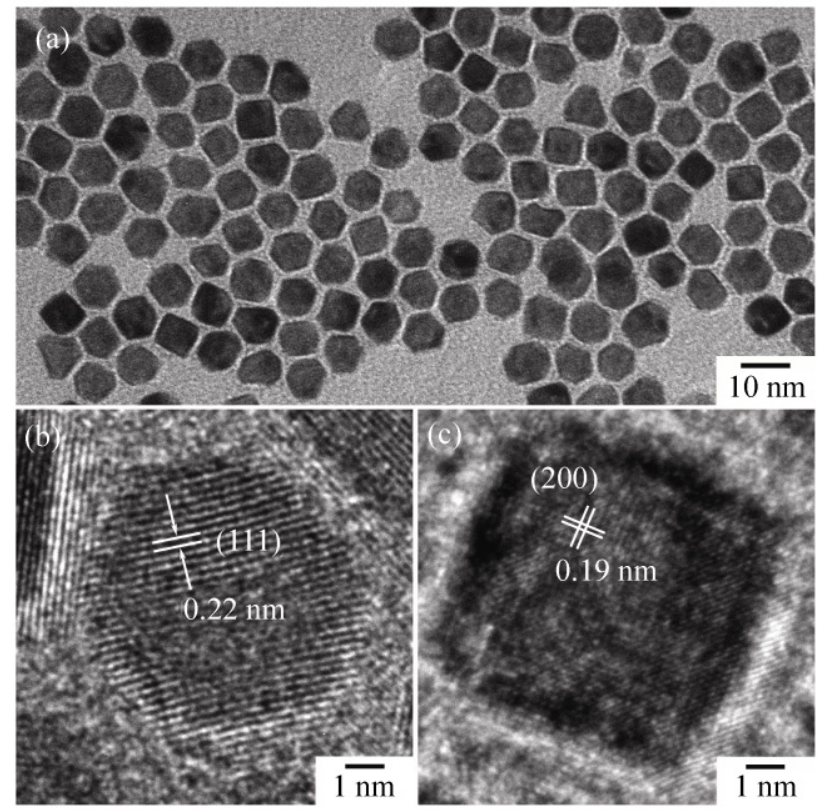

Figure 1 (a) TEM image of HDA-capped $\mathrm{Pt}_{3} \mathrm{Ni}$ nanoparticles showing the uniform size, and high-resolution TEM images of (b) a representative truncated octahedron with (111) lattice planes, and (c) a cube with (200) lattice planes 
(Fig. 1(b)), which closely matches that of the (111) plane of $\mathrm{Pt}_{3} \mathrm{Ni}$ alloy. The cubes have a $d$-spacing of $0.19 \mathrm{~nm}$ (Fig. 1(c)), which matches that of the (200) plane of $\mathrm{Pt}_{3} \mathrm{Ni}$ alloy.

Figure 2 shows a representative PXRD pattern and EDX analysis of the nanoparticles shown in Fig. 1 made using HDA as the capping agent. The powder PXRD pattern can be indexed to (111), (200), (220), and (311) diffractions of a face-centered-cubic (fcc) structure with the peak positions in between those for pure Pt and Ni metals (Fig. 2(a)). The lattice constant was calculated to be $3.84 \AA$ for the $90 \%$ truncated octahedral $\mathrm{Pt}_{3} \mathrm{Ni}\left(t, o-\mathrm{Pt}_{3} \mathrm{Ni}\right)$ by fitting all four peaks of the PXRD curve. This value corresponds to a composition close to $\mathrm{Pt}_{3} \mathrm{Ni}$ calculated according to Vegard's law, assuming $a_{\mathrm{Pt}}=3.923 \AA$ and $a_{\mathrm{Ni}}=$ $3.524 \AA$. The crystalline domain size was determined

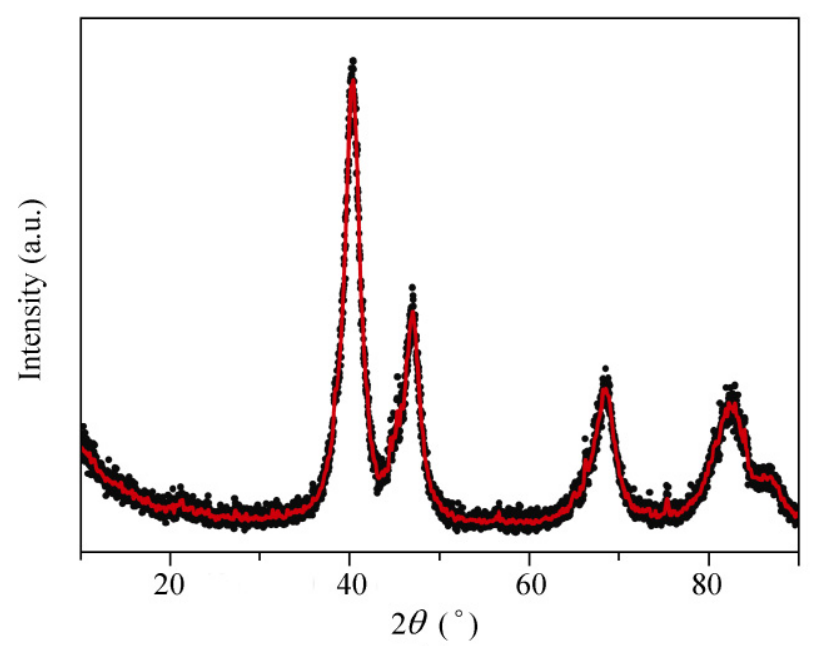

(a)

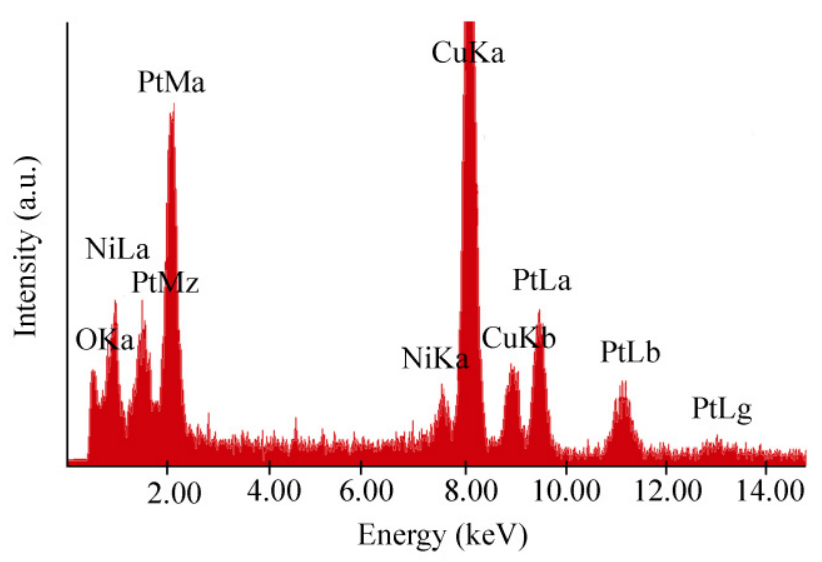

(b)

Figure 2 (a) PXRD pattern and (b) EDX spectrum of the $\mathrm{Pt}_{3} \mathrm{Ni}$ nanoparticles to be $\sim 7 \mathrm{~nm}$ using the full width at half-maximum (HWHM) of the (111) diffraction peak and the Debye-Scherrer formulation. This value is close to the dimension shown in the TEM image (Fig. 1(a)). EDX analysis shows the weight percentage composition of the bimetallic material was $8.6 \% \mathrm{Ni}$ and $91.4 \% \mathrm{Pt}$. These values correspond to a $\mathrm{Pt} / \mathrm{Ni}$ atomic ratio of $76 / 24$, which is very close to the composition $\mathrm{Pt}_{3} \mathrm{Ni}$.

\subsection{Effect of varying the amine capping agents and acid additives}

Long carbon chain amines and acids generally play important roles in the size and shape control in non-hydrolytic syntheses of nanoparticles. In this work, we explored the effects of four N-terminal amines with different carbon chain lengths on the shape control of $\mathrm{Pt}_{3} \mathrm{Ni}$ alloys. Figure 3 shows the nanoparticles made by using amines with different alkyl- or alkenyl chain lengths, which varied from 8 to 18 carbon atoms, $\left(\mathrm{C}_{8} \mathrm{H}_{17} \mathrm{NH}_{2}, \mathrm{C}_{12} \mathrm{H}_{25} \mathrm{NH}_{2}, \mathrm{C}_{18} \mathrm{H}_{37} \mathrm{NH}_{2}\right.$, $\mathrm{C}_{18} \mathrm{H}_{35} \mathrm{NH}_{2}$ ). All other reaction conditions were kept the same as for HDA. The shape of $\mathrm{Pt}_{3} \mathrm{Ni}$ nanoparticles produced using octylamine $\left(\mathrm{C}_{8} \mathrm{H}_{17} \mathrm{NH}_{2}\right)$ was not uniform (Fig. 3(a)). It seems that octylamine does not have strong facet-selected adsorption on $\mathrm{Pt}_{3} \mathrm{Ni}$ surfaces. This short alkyl chain amine can occupy the active growth sites and inhabit the adsorption of AAA, which is known to show competitive binding on metal surfaces with certain amines, such as HDA [11, 28-30]. When long carbon chain amines including dodecylamine and octadecylamine were used, the shape and size of the nanoparticles became uniform (Figs. 3(b) and 3(c)) as previously observed for HDA (Fig. 1(a)). The population of truncated octahedra and cubes also changed. Truncated octahedral $\mathrm{Pt}_{3} \mathrm{Ni}$ nanoparticles were essentially the only product when dodecylamine was used as the capping agent (Fig. 3(b)). The product consisted of about $70 \%$ of truncated octahedra when octadecylamine was used (Fig. 3(c). The remaining 30\% was largely composed of nanocubes. With oleylamine, which has the same carbon chain length as octadecylamine but contains a $\mathrm{C}=\mathrm{C}$ double bond, shape-control was lost (Fig. 3(d)). While it is effective in controlling the size and shape of some metal and alloy nanoparticles [2], oleylamine is not effective under our reaction conditions. 


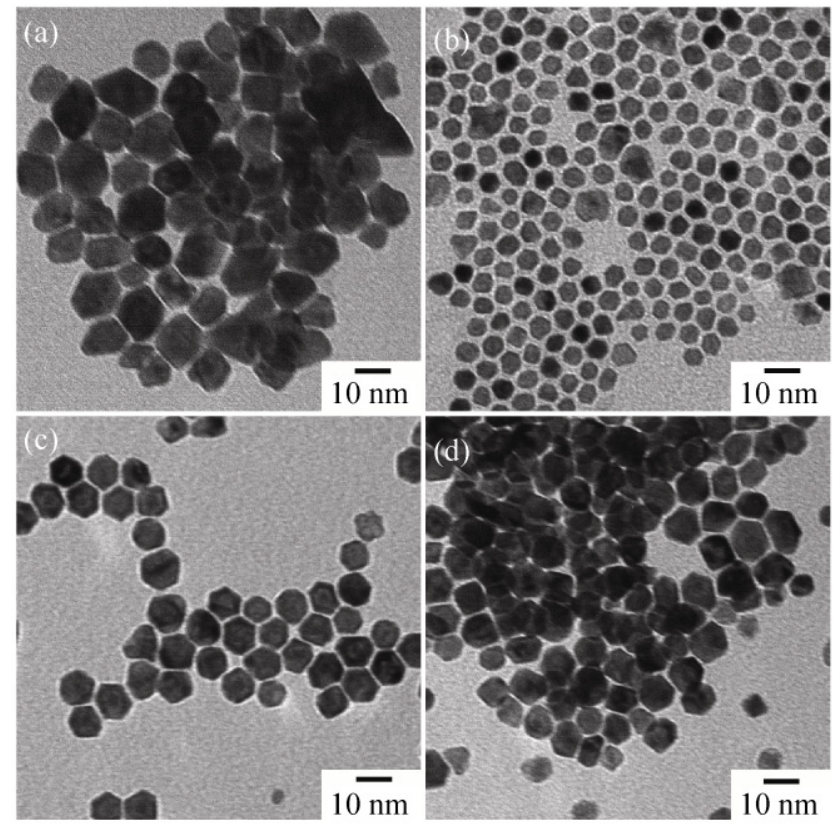

Figure 3 TEM images of $\mathrm{Pt}_{3} \mathrm{Ni}$ nanoparticles synthesized in the presence of different N-terminal amines: (a) octylamine, (b) dodecylamine, (c) octadecylamine, and (d) oleylamine

Based on these observations, it seems that additives such as HDA and dodecylamine, balanced the growth along the $<111>$ and $<100>$ directions, resulting in the formation of a predominance of truncated octahedra, in which both $\{111\}$ and $\{100\}$ facets are exposed, and a few cubes, which have only $\{100\}$ facets exposed. When the length of the alkyl group was increased (octadecylamine), the population of the cubic shape increased, indicating that the optimal alkyl group is necessary to create the right interfacial energy near the $\{111\}$ and $\{100\}$ facets for selected growth.

The particle size of the samples also varied, with an average of $5.4 \mathrm{~nm} \pm 0.6 \mathrm{~nm}$ for dodecylamine-capped particles (Fig. 3(b)), $8.3 \mathrm{~nm} \pm 0.5 \mathrm{~nm}$ for HDA-capped nanoparticles (Fig. 1(a)), and $8.9 \mathrm{~nm} \pm 0.7 \mathrm{~nm}$ for octadecylamine-capped nanoparticles (Fig. 3(c)). This difference in size might be related to variations in the weak reducing ability of the various amines [31,32], although the main reducing agents used were still TBAB and the 1,2-alkanediol.

\subsection{Effect of varying the bulky acid additives}

Figure 4 shows TEM images of HDA-capped $\mathrm{Pt}_{3} \mathrm{Ni}$ nanoparticles made in the presence of ACA and

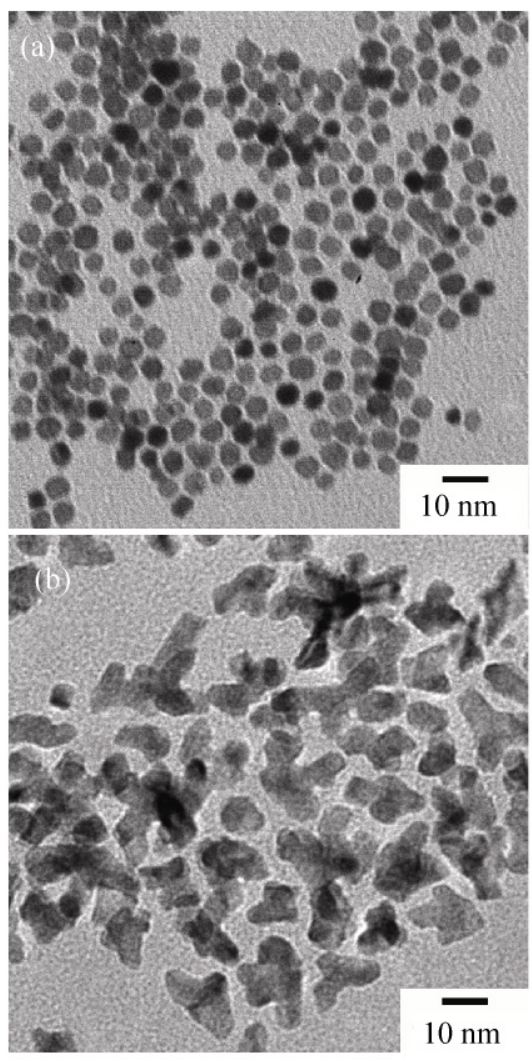

Figure 4 TEM images of HDA-capped $\mathrm{Pt}_{3} \mathrm{Ni}$ nanoparticles synthesized in the presence of (a) ACA, and (b) $L$-ascorbic acid

$L$-ascorbic acid, instead of AAA. The size and shape of $\mathrm{Pt}_{3} \mathrm{Ni}$ nanoparticles made using ACA (Fig. 4(a)) were similar to those made in the presence of AAA under similar reaction conditions (Fig. 1(a)). When $L$-ascorbic acid, which does not contain an adamantane functional group, was employed, no well-defined shapes were obtained, with various irregular morphologies including short tripods (Fig. 4(b)) being formed. Thus, while slight changes in alkyl chain length do not lead to dramatic transformations in shape, the bulky adamantane group is an important structural factor in shape control. This observation suggests that kinetic exchange between bulky adamantane and long chain amine groups on the metal surface is critical in the controlling the shape [11, 28-30].

The relative growth rates along (111) and (100) surfaces largely determine whether $\{111\}$ facetdominant octahedra or $\{100\}$ facet-dominant cubes are formed. The preferred growth is directly related to the surface energy of these two types of facets. In 
these $\mathrm{Pt}_{3} \mathrm{Ni}$ nanoparticle systems, controlling the reaction rate by varying the relative surface energies of (111) and (100), and the reduction rate of metal precursors were both found to be feasible. The use of long carbon chain amines and, to a lesser extent, bulky acid additives alters the relative energies of (111) and (100) surfaces. Long chain amines such as HDA favored the formation of octahedra and truncated octahedra that possess a high ratio of $\{111\}$ facets. The ratio of $(111) /(100)$ surfaces increased as the population changed from $90 \%$ to $100 \%$ truncated octahedra, which was achieved when HDA was replaced by a shorter alkyl chain amine (dodecylamine); this is probably due to the strong capping ability of the latter amine on the (111) surface.

Besides their ability to compete with long-chain amines in binding on metal surfaces, the acid additives can also selectively react with $\mathrm{Ni}$ atoms on the growing surfaces of $\mathrm{Pt}_{3} \mathrm{Ni}$ nanoparticles. In general, carboxylic acids should bind strongly with less noble metals such as $\mathrm{Fe}$ and $\mathrm{Ni}$, while amines interact preferentially with noble metals, such as $\mathrm{Au}$ and $\mathrm{Pt}$ [33]. In the case of $\mathrm{a} \mathrm{Pt}_{3} \mathrm{Ni}$ alloy, the acid functional group can react with $\mathrm{Ni}$ at $190{ }^{\circ} \mathrm{C}$, which affects the relative surface energies of (100) and (111). Overall, the bulky adamantane functional group seems to be critical in achieving shapes which are dominated by the (111) surface.

\subsection{Effect of varying the reducing agents}

The role of amines and acid additives is primarily to control the surface energy and reaction kinetics of nanoparticle formation. To examine the effect of varying the reducing agents on the shape control, we added DDD $\left(\mathrm{C}_{12} \mathrm{H}_{24}(\mathrm{OH})_{2}\right)$ or DD $\left(\mathrm{C}_{10} \mathrm{H}_{20}(\mathrm{OH})_{2}\right)$ instead of HDD $\left(\mathrm{C}_{16} \mathrm{H}_{32}(\mathrm{OH})_{2}\right)$ to our non-hydrolytic reaction system. When DDD was used, nanoparticles grew into irregular shapes, suggesting there was insufficient reaction time for Ostwald (size-focused) ripening, which is important for the formation of uniform particles (Fig. 5(a)). With DD was employed, dendrite-like growth became pronounced (Fig. 5(b)). Reaction under these conditions was relatively fast, a likely reason for the uncontrollable anisotropic growth. The change in the alkyl chain length of the

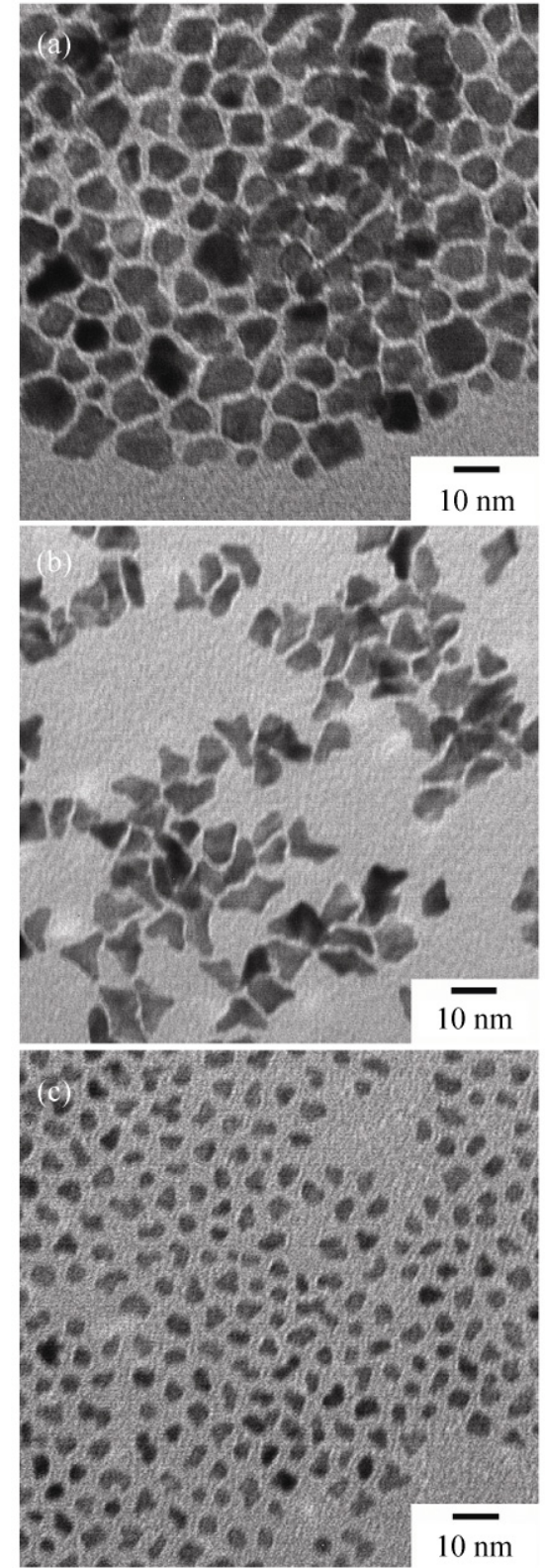

Figure 5 TEM images of $\mathrm{Pt}_{3} \mathrm{Ni}$ nanoparticles reduced with (a) TBAB and DDD and (b) TBAB and DD, and (c) TBAB with no diol

1,2-alkanediols could also affect the relative surface energies of the $\mathrm{Pt}_{3} \mathrm{Ni}$ nanoparticles.

Figure 5(c) shows a TEM image of $\mathrm{Pt}_{3} \mathrm{Ni}$ nanoparticles formed by reduction with the strong reductant, $\mathrm{TBAB}$, alone rather than mixed with a diol as a weak reducing agent. The size of the resulting nanoparticles was around $4-5 \mathrm{~nm}$ and the shapes were not uniform. As TBAB is a strong reducing agent, a burst of nuclei occurred readily and the subsequent growth was also 
fast. Under such conditions, shape was not easily controllable because the growth stage was too short.

When the HDD/TBAB molar ratio was decreased from 5.44 (as for the sample shown in Fig. 1(a)) to 1.36, the size of the particles obtained was 3-4 nm (Fig. 6), substantially smaller than those made with a HDD/TBAB molar ratio of 5.44. Thus the size of the nanoparticles can clearly be tuned by changing the rate of reduction of metal precursors by adjusting the relative amounts of strong (TBAB) and weak (HDD) reducing agents. As a strong reductant, TBAB plays the major role in the nucleation stage, whereas the 1,2-alkanediol, the weak reductant, is important in affecting the reaction rate and surface energy during the growth stage.

\subsection{Effect of varying the reaction time}

As the ripening step is critical in the size control, we further examined the time evolution of the $\mathrm{Pt}_{3} \mathrm{Ni}$ nanoparticles. The well-defined $5.9 \mathrm{~nm} \pm 0.5 \mathrm{~nm}$ truncated octahedral $\mathrm{Pt}_{3} \mathrm{Ni}$ formed at $30 \mathrm{~min}$ (Fig. 7(a)). The edge length of these nanoparticles was about 70\% of those after reaction for $1 \mathrm{~h}$ (Fig. 1(a)). The nanoparticles became mostly spherical and uniform in size after $2 \mathrm{~h}$, most likely due to the Ostwald ripening in which the thermodynamically unstable atoms at the corners and edges dissolved in solution during the growth stage (Fig. 7(b)). There were a few truncated octahedral nanoparticles with smooth corners, which indicates that the size and shape evolution is timedependent.

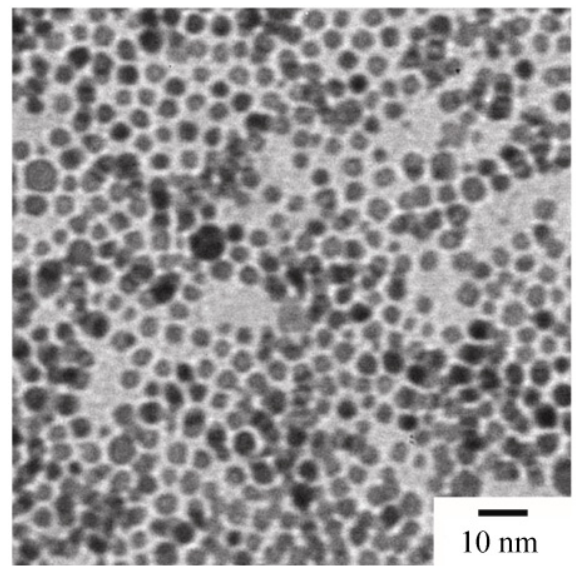

Figure 6 TEM image of $\mathrm{Pt}_{3} \mathrm{Ni}$ nanoparticles formed with a $\mathrm{HDD} / \mathrm{TBAB}$ molar ratio of 1.36 using HDA as capping agent in the presence of AAA

\subsection{Electrocatalytic properties}

We studied the electrocatalytic properties in alkaline solutions using three different shaped-defined $\mathrm{Pt}_{3} \mathrm{Ni} / \mathrm{C}$ catalysts with 70\% (Fig. 7(a)), 90\% (Fig. 1(a)) and $100 \%$ (Fig. 3(b)) of the particles having truncated octahedral shape. Figure 8 shows the $\mathrm{CV}$ curves of the $\mathrm{Pt}_{3} \mathrm{Ni} / \mathrm{C}$ catalysts in $0.5 \mathrm{~mol} / \mathrm{L} \mathrm{H}_{2} \mathrm{SO}_{4}$. In the backward (negative) scan, the peak centered at $0.23 \mathrm{~V}$ is due to the hydrogen adsorption on the $\{110\}$ facets and the peak at $0.12 \mathrm{~V}$ arises from the $\{100\}$ facets. The featureless box-like broad peak between $0.1 \mathrm{~V}$ and $0.3 \mathrm{~V}$ represents hydrogen adsorption on the $\{111\}$ facets [34]. The sample with $70 \% t, o-\mathrm{Pt}_{3} \mathrm{Ni} / \mathrm{C}$ shows a weak adsorption on the (111) surface. The $100 \%$ $t, o-\mathrm{Pt}_{3} \mathrm{Ni}$ sample shows the strongest (111) surface adsorption among the three catalysts. These results are generally consistent with the TEM images of these $\mathrm{Pt}_{3} \mathrm{Ni}$ nanoparticles (Figs. 7(a), 1(a), and 3(b)

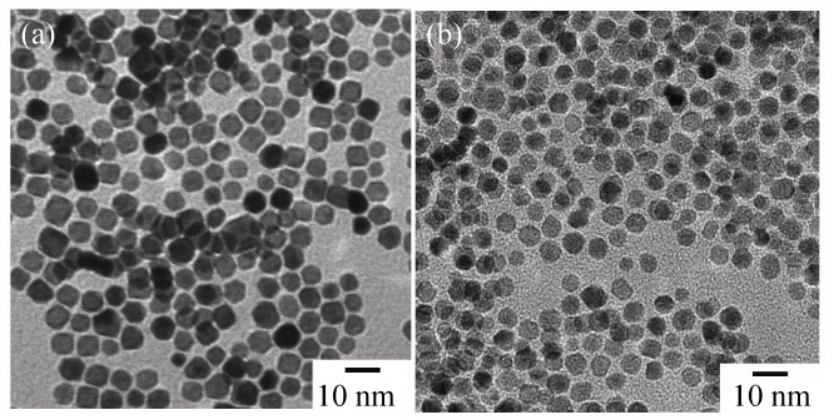

Figure 7 TEM images showing the shape of $\mathrm{Pt}_{3} \mathrm{Ni}$ nanoparticles after reaction for (a) $30 \mathrm{~min}$ and (b) $120 \mathrm{~min}$

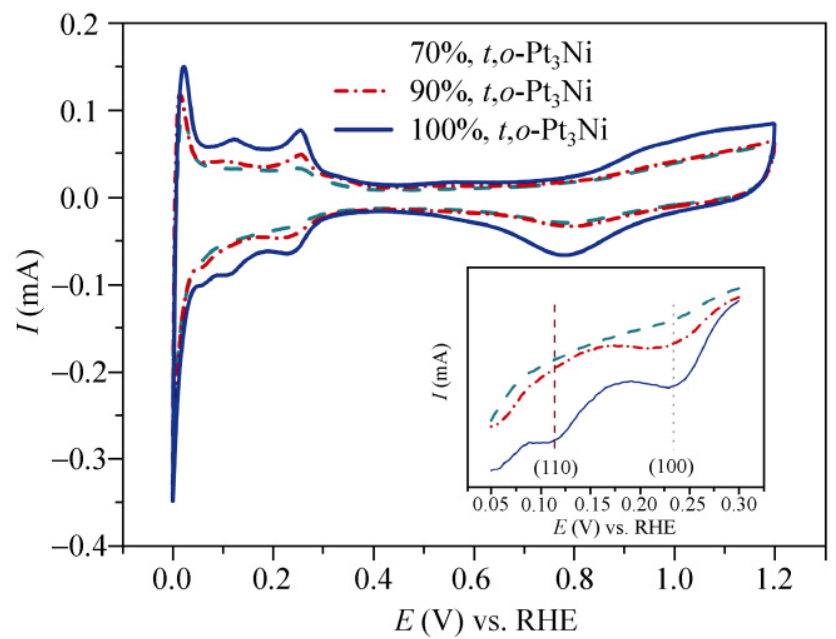

Figure $8 \mathrm{CV}$ curves in $0.5 \mathrm{~mol} / \mathrm{L} \mathrm{H}_{2} \mathrm{SO}_{4}$ of three $\mathrm{Pt}_{3} \mathrm{Ni}$ catalysts with different proportions of $t, o-\mathrm{Pt}_{3} \mathrm{Ni}$. The inset shows the enlarged hydrogen adsorption region between 0.05 and $0.30 \mathrm{~V}$ 
respectively).

Figure 9 shows the electrochemical properties of these $\mathrm{Pt}_{3} \mathrm{Ni} / \mathrm{C}$ catalysts and a $\mathrm{Pt}$ reference catalyst in $0.1 \mathrm{~mol} / \mathrm{L} \mathrm{KOH}$. From the $\mathrm{CV}$ and polarization curves, we obtained the normalized ORR activities. The areaspecific activity of $\mathrm{Pt}_{3} \mathrm{Ni}$ at $0.9 \mathrm{~V}$ was $0.56 \mathrm{~mA} / \mathrm{cm}^{2}(\mathrm{Pt})$ for $70 \% t, o-\mathrm{Pt}_{3} \mathrm{Ni} / \mathrm{C}, 0.57 \mathrm{~mA} / \mathrm{cm}^{2}(\mathrm{Pt})$ for $90 \% t, o-\mathrm{Pt}_{3} \mathrm{Ni} / \mathrm{C}$ and $0.76 \mathrm{~mA} / \mathrm{cm}^{2}(\mathrm{Pt})$ for $100 \% t, o-\mathrm{Pt}_{3} \mathrm{Ni} / \mathrm{C}$. All of these values are higher than the value, $0.17 \mathrm{~mA} / \mathrm{cm}^{2}(\mathrm{Pt})$, for $\mathrm{Pt} / \mathrm{C}$. The $\mathrm{Pt}_{3} \mathrm{Ni} / \mathrm{C}$ catalyst with the highest specific activity represents a 3.5-fold enhancement over $\mathrm{Pt} / \mathrm{C}$. The corresponding ORR mass activity $\left(i_{\mathrm{m}}\right)$ was 0.30 $\mathrm{A} / \mathrm{mg}(\mathrm{Pt})$ for the $100 \% t, o-\mathrm{Pt}_{3} \mathrm{Ni} / \mathrm{C}$ catalyst, which is more than twice that of the $\mathrm{Pt} / \mathrm{C}$ catalyst $(0.14 \mathrm{~A} / \mathrm{mg}(\mathrm{Pt}))$.

The electrocatalytic activity of the $t, o-\mathrm{Pt}_{3} \mathrm{Ni} / \mathrm{C}$ catalysts was quantitatively examined as a function of rotation speed of the rotating disk electrode ranging from 400 to $2500 \mathrm{rpm}$ (Figs. 10(a)-10(c)). The well-defined limiting current curves at various rotation speeds suggest that the charge transfer is

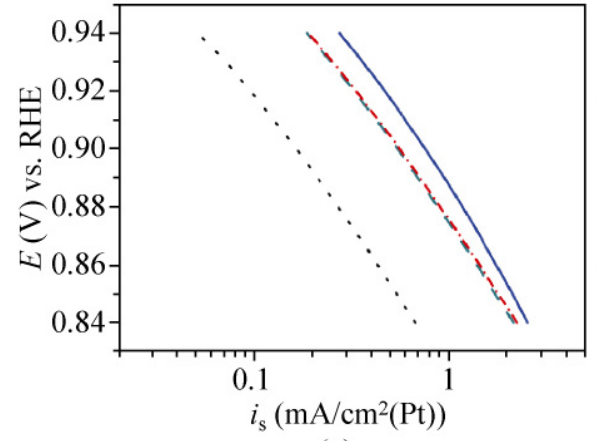

(a)

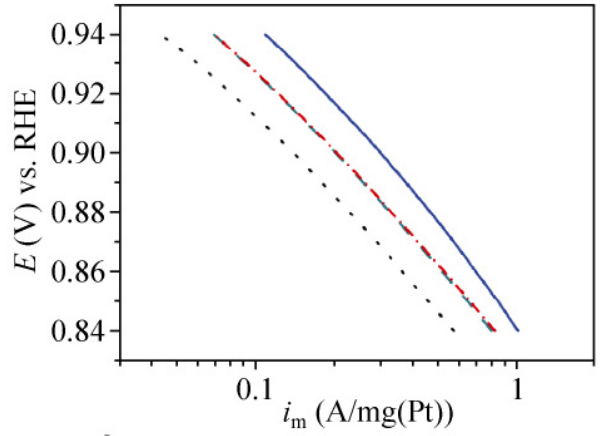

(b)

Figure 9 (a) Area-specific $\left(\mathrm{mA} / \mathrm{cm}^{2}(\mathrm{Pt})\right)$ and (b) mass $(\mathrm{A} / \mathrm{mg}(\mathrm{Pt})) \mathrm{ORR}$ activities for the $t, o-\mathrm{Pt}_{3} \mathrm{Ni}$ and reference Pt catalysts. (black dotted line: Pt; green dash line: $70 \% t, o-\mathrm{Pt}_{3} \mathrm{Ni}$; red dotted dash line: $90 \% t, o-\mathrm{Pt}_{3} \mathrm{Ni}$; and blue solid line: $100 \% t, o-\mathrm{Pt}_{3} \mathrm{Ni}$ )

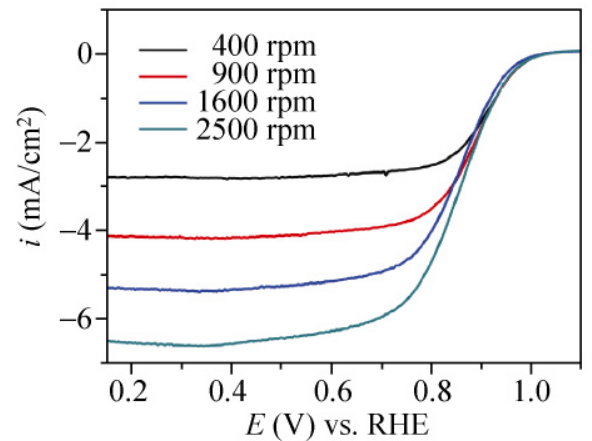

(a)

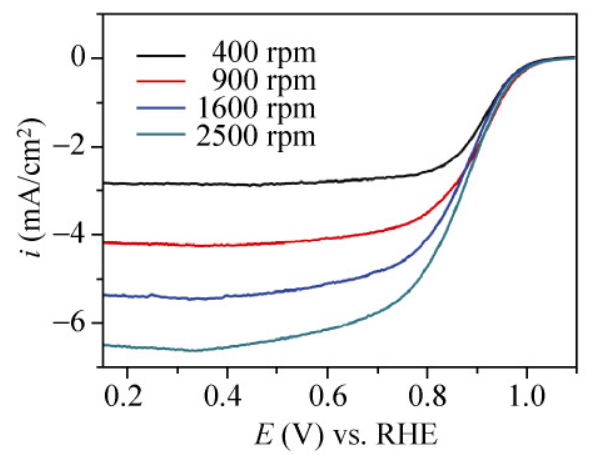

(c)

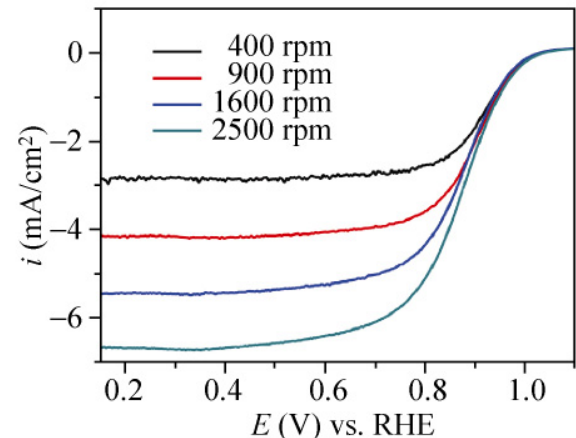

(b)

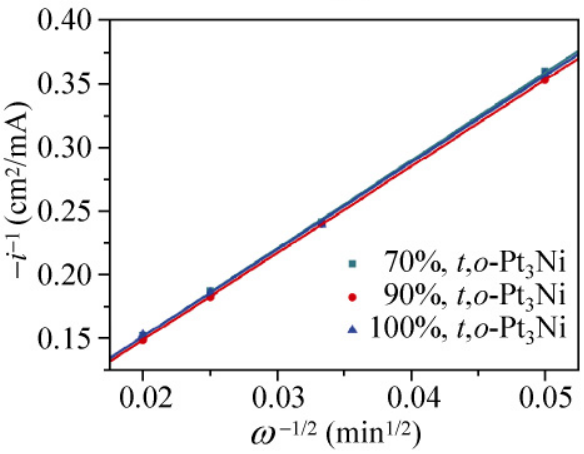

(d)

Figure 10 RDE voltammograms for the ORR of (a) $70 \%$, (b) $90 \%$ and (c) $100 \% t, o-\mathrm{Pt}_{3} \mathrm{Ni} / \mathrm{C}$ electrocatalysts at various rotation rates, and (d) Koutecky-Levich plots of the rotating disk current at $0.3 \mathrm{~V}$ (vs. RHE). The tests were conducted in $\mathrm{O}_{2}$-saturated $0.1 \mathrm{~mol} / \mathrm{L} \mathrm{KOH}$ solution and the scan rate was kept at $10 \mathrm{mV} / \mathrm{s}$ 
much faster than the mass transfer during ORR [7]. Figure 10(d) shows the Koutecky-Levich plots as a function of ORR working potentials for these three $t, o-\mathrm{Pt}_{3} \mathrm{Ni} / \mathrm{C}$ catalysts. These curves overlap with each other, indicating that the number of electrons transferred in ORR barely changes within the potential region of the limiting-current.

We further compared the slopes of these curves with the theoretically calculated values for the fourelectron reduction of $\mathrm{O}_{2}$ using the modified KouteckyLevich equation[7] for thin film-coated electrodes. The measured current density $(i)$ is related to the kinetic current density $\left(i_{\mathrm{k}}\right)$, and the diffusion-limiting current density $\left(i_{\mathrm{d}}\right)$, can be obtained using the following equation:

$$
i_{\mathrm{d}}=0.2 n F D_{\mathrm{o}}^{2 / 3} C_{\mathrm{o}} v^{-1 / 6} \omega^{1 / 2}
$$

where $n$ is the number of electrons transferred, $F$ is the Faraday constant, $D_{\mathrm{o}}$ is the diffusion coefficient of $\mathrm{O}_{2}$ gas $\left(1.9 \times 10^{-5} \mathrm{~cm}^{2} / \mathrm{s}\right), v$ is the kinematic viscosity of water $\left(0.01 \mathrm{~cm}^{2} / \mathrm{s}\right), C_{\mathrm{o}}$ is the concentration of $\mathrm{O}_{2}$ gas in dilute aqueous solution $\left(1.1 \times 10^{-5} \mathrm{~mol} / \mathrm{cm}^{3}\right)$ and $\omega$ is the rotation rate of the electrode in unit of $\mathrm{rpm}$. The kinetic current density, $i_{\mathrm{k}}$ is an intrinsic property of the catalyst and can be obtained based the relationship between the measured current density and the rotation rate, which can be described as follows:

$$
\frac{1}{i_{\text {disk }}}=\frac{1}{i_{\mathrm{k}}}+\frac{1}{i_{\mathrm{d}}}=\frac{1}{i_{\mathrm{k}}}+\frac{1}{B \omega^{1 / 2}}
$$

where $B$ is the Levich constant that can be obtained from the slope of the Koutecky-Levich plot. Using the appropriate numerical values, the relationship between the Levich constant $B$ and the number of electrons $n$ transferred during the ORR can be simply obtained based on the following equation:

$$
B=0.2 n F D_{\mathrm{o}}^{2 / 3} C_{\mathrm{o}} v^{-1 / 6}=3.5 \times 10^{-5} n
$$

From the slopes of the curves shown in Fig. 10(d), we obtained values of $n$ of $3.5 \pm 0.1,3.6 \pm 0.1$ and $3.6 \pm$ 0.1 , respectively, for $70 \%, 90 \%$ and $100 \% t, o-\mathrm{Pt}_{3} \mathrm{Ni}$ catalysts at $0.3 \mathrm{~V}$ (vs. RHE). This indicates that in alkaline aqueous media, the reduction from $\mathrm{O}_{2}$ to $\mathrm{OH}^{-}$by
Table 1 ECSA, mass- and area-specific ORR activities of $\mathrm{Pt}_{3} \mathrm{Ni}$ and Pt catalysts in $0.1 \mathrm{~mol} / \mathrm{L} \mathrm{KOH}^{\mathrm{a}}$

\begin{tabular}{ccccc}
\hline Sample & $\begin{array}{c}\mathrm{Pt} \text { loading } \\
\left(\mathrm{mg}(\mathrm{Pt}) / \mathrm{cm}^{2}\right)\end{array}$ & $\begin{array}{c}\text { ECSA } \\
\left(\mathrm{m}^{2} / \mathrm{g}(\mathrm{Pt})\right)\end{array}$ & $\begin{array}{c}\text { Mass } \\
\text { activity } \\
(\mathrm{A} / \mathrm{mg}(\mathrm{Pt}))\end{array}$ & $\begin{array}{c}\text { Area-specific } \\
\text { activity } \\
\left(\mathrm{mA} / \mathrm{cm}^{2}(\mathrm{Pt})\right)\end{array}$ \\
\hline $\begin{array}{c}100 \% \\
t, o-\mathrm{Pt}_{3} \mathrm{Ni} / \mathrm{C} \\
\begin{array}{c}90 \% \\
t, o-\mathrm{Pt}_{3} \mathrm{Ni} / \mathrm{C}\end{array}\end{array}$ & 9.3 & 39.5 & 0.30 & 0.76 \\
$\begin{array}{c}70 \% \\
t, o-\mathrm{Pt} t_{3} \mathrm{Ni} / \mathrm{C}\end{array}$ & 9.3 & 36.5 & 0.20 & 0.57 \\
$\mathrm{Pt} / \mathrm{C}$ & 11 & 37.0 & 0.20 & 0.56 \\
\hline
\end{tabular}

${ }^{a}$ The activity was measured at $0.9 \mathrm{~V}$ vs. RHE.

these $t, o-\mathrm{Pt}_{3} \mathrm{Ni}$ catalysts can be treated as a direct fourelectron process controlled by mass diffusion $[7,17,35]$.

\section{Conclusions}

The effects of varying key factors, including the capping agent, reducing agent and reaction time on the size, shape and composition of $\mathrm{Pt}_{3} \mathrm{Ni}$ nanoparticles have been demonstrated. While the shape and size of the particles can be affected by changing almost any of the reaction parameters studied, the use of adamantane-containing functional groups, and a mixture of strong and weak reducing agents are especially important in obtaining good control over particle shape. In alkaline solution, the shapecontrolled $\mathrm{Pt}_{3} \mathrm{Ni}$ catalysts show very high kinetic activity in the ORR reaction. In addition, the $\mathrm{Pt}_{3} \mathrm{Ni}$ (111) surface has a much higher ORR catalytic activity than that of the (100) surface; the same trend has previously been demonstrated for these catalysts under acidic conditions.

\section{Acknowledgements}

This work was supported by the National Science Foundation (DMR-0449849). It made use of the Shared Facilities at University of Rochester River Campus EM Lab sponsored in part by the DOE.

Open Access: This article is distributed under the terms of the Creative Commons Attribution Noncommercial License which permits any noncommercial use, distribution, and reproduction in any medium, provided the original author(s) and source are credited. 


\section{References}

[1] Wagner, F. T.; Lakshmanan, B.; Mathias, M. F. Electrochemistry and the future of the automobile. J. Phys. Chem. Lett. 2010, 1, 2204-2219.

[2] Peng, Z. M.; Yang, H. Designer platinum nanoparticles: Control of shape, composition in alloy, nanostructure and electrocatalytic property. Nano Today 2009, 4, 143-164.

[3] Steele, B. C. H.; Heinzel, A. Materials for fuel-cell technologies. Nature 2001, 414, 345-352.

[4] Winter, M.; Brodd, R. J. What are batteries, fuel cells, and supercapacitors? Chem. Rev. 2004, 104, 4245-4269.

[5] Chen, A. C.; Holt-Hindle, P. Platinum-based nanostructured materials: Synthesis, properties, and applications. Chem. Rev. 2010, 110, 3767-3804.

[6] Bing, Y. H.; Liu, H. S.; Zhang, L.; Ghosh, D.; Zhang, J. J. Nanostructured Pt-alloy electrocatalysts for PEM fuel cell oxygen reduction reaction. Chem. Soc. Rev. 2010, 39, 2184-2202.

[7] Gasteiger, H. A.; Kocha, S. S.; Sompalli, B.; Wagner, F. T. Activity benchmarks and requirements for Pt, Pt-alloy, and non-Pt oxygen reduction catalysts for PEMFCs. Appl. Catal. B-Environ. 2005, 56, 9-35.

[8] Stamenkovic, V. R.; Fowler, B.; Mun, B. S.; Wang, G. F.; Ross, P. N.; Lucas, C. A.; Markovic, N. M. Improved oxygen reduction activity on $\mathrm{Pt}_{3} \mathrm{Ni}(111)$ via increased surface site availability. Science 2007, 315, 493-497.

[9] Lim, B.; Jiang, M. J.; Camargo, P. H. C.; Cho, E. C.; Tao, J.; Lu, X. M.; Zhu, Y. M.; Xia, Y. A. Pd-Pt bimetallic nanodendrites with high activity for oxygen reduction. Science 2009, 324, 1302-1305.

[10] Peng, Z. M.; Yang, H. Synthesis and oxygen reduction electrocatalytic property of Pt-on-Pd bimetallic heteronanostructures. J. Am. Chem. Soc. 2009, 131, 7542-7543.

[11] Wu, J.; Zhang, J.; Peng, Z.; Yang, S.; Wagner, F. T.; Yang, H. Truncated octahedral $\mathrm{Pt}_{3} \mathrm{Ni}$ oxygen reduction reaction electrocatalysts. J. Am. Chem. Soc. 2010, 132, 4984-4985.

[12] Peng, Z. M.; Wu, J. B.; Yang, H. Synthesis and oxygen reduction electrocatalytic property of platinum hollow and platinum-on-silver nanoparticles. Chem. Mat. 2010, 22, 1098-1106.

[13] Zhang, J.; Yang, H. Z.; Fang, J. Y.; Zou, S. Z. Synthesis and oxygen reduction activity of shape-controlled $\mathrm{Pt}_{3} \mathrm{Ni}$ nanopolyhedra. Nano Lett. 2010, 10, 638-644.

[14] Koh, S.; Strasser, P. Electrocatalysis on bimetallic surfaces: Modifying catalytic reactivity for oxygen reduction by voltammetric surface dealloying. J. Am. Chem. Soc. 2007, $129,12624-12625$.

[15] Lee, H. J.; Habas, S. E.; Somorjai, G. A.; Yang, P. D.
Localized Pd overgrowth on cubic Pt nanocrystals for enhanced electrocatalytic oxidation of formic acid. J. Am. Chem. Soc. 2008, 130, 5406-5407.

[16] Wang, C.; Daimon, H.; Lee, Y.; Kim, J.; Sun, S. Synthesis of monodisperse $\mathrm{Pt}$ nanocubes and their enhanced catalysis for oxygen reduction. J. Am. Chem. Soc. 2007, 129, 69746975.

[17] Greeley, J.; Stephens, I. E. L.; Bondarenko, A. S.; Johansson, T. P.; Hansen, H. A.; Jaramillo, T. F.; Rossmeisl, J.; Chorkendorff, I.; Norskov, J. K. Alloys of platinum and early transition metals as oxygen reduction electrocatalysts. Nat. Chem. 2009, 1, 552-556.

[18] Chen, S.; Ferreira, P. J.; Sheng, W. C.; Yabuuchi, N.; Allard, L. F.; Shao-Horn, Y. Enhanced activity for oxygen reduction reaction on " $\mathrm{Pt}_{3} \mathrm{Co}$ " nanoparticles: Direct evidence of percolated and sandwich-segregation structures. J. Am. Chem. Soc. 2008, 130, 13818-13819.

[19] Shao, Y. Y.; Liu, J.; Wang, Y.; Lin, Y. H. Novel catalyst support materials for PEM fuel cells: Current status and future prospects. J. Mater. Chem. 2009, 19, 46-59.

[20] Zhang, J.; Sasaki, K.; Sutter, E.; Adzic, R. R. Stabilization of platinum oxygen-reduction electrocatalysts using gold clusters. Science 2007, 315, 220-222.

[21] Shao, Y. Y.; Zhang, S.; Kou, R.; Wang, X. Q.; Wang, C. M.; Dai, S.; Viswanathan, V.; Liu, J.; Wang, Y.; Lin, Y. H. Noncovalently functionalized graphitic mesoporous carbon as a stable support of $\mathrm{Pt}$ nanoparticles for oxygen reduction. J. Power Sources 2010, 195, 1805-1811.

[22] Lu, S. F.; Pan, J.; Huang, A. B.; Zhuang, L.; Lu, J. T. Alkaline polymer electrolyte fuel cells completely free from noble metal catalysts. Proc. Natl. Acad. Sci. U. S. A. 2008, 105, 20611-20614.

[23] Meng, H.; Wu, M.; Hu, X. X.; Nie, M.; Wei, Z. D.; Shen, P. $\mathrm{K}$. Selective cathode catalysts for mixed-reactant alkaline alcohol fuel cells. Fuel Cells 2006, 6, 447-450.

[24] Gu, S.; Cai, R.; Luo, T.; Chen, Z. W.; Sun, M. W.; Liu, Y.; He, G. H.; Yan, Y. S. A soluble and highly conductive ionomer for high-performance hydroxide exchange membrane fuel cells. Angew. Chem. Int. Edit. 2009, 48, 6499-6502.

[25] Markovic, N. M.; Ross, P. N. Surface science studies of model fuel cell electrocatalysts. Surf. Sci. Rep. 2002, 45, 117-229.

[26] Spendelow, J. S.; Wieckowski, A. Electrocatalysis of oxygen reduction and small alcohol oxidation in alkaline media. Phys. Chem. Chem. Phys. 2007, 9, 2654-2675.

[27] Zhang, H. W.; Zhou, Z. T. Alkaline polymer electrolyte membranes from quaternized poly(phthalazinone ether ketone) for direct methanol fuel cell. J. Appl. Polym. Sci. 2008, 110, 1756-1762. 
[28] Maksimuk, S.; Teng, X.; Yang, H. Roles of twin defects in the formation of platinum multipod nanocrystals. J. Phys. Chem. C 2007, 111, 14312-14319.

[29] Dameron, A. A.; Mullen, T. J.; Hengstebeck, R. W.; Saavedra, H. M.; Weiss, P. S. Origins of displacement in 1-adamantanethiolate self-assembled monolayers. J. Phys. Chem. C 2007, 111, 6747-6752.

[30] Mullen, T. J.; Dameron, A. A.; Saavedra, H. M.; Williams, M. E.; Weiss, P. S. Dynamics of solution displacement in 1-adamantanethiolate self-assembled monolayers. J. Phys. Chem. C 2007, 111, 6740-6746.

[31] Huo, Z. Y.; Tsung, C. K.; Huang, W. Y.; Zhang, X. F.; Yang, P. D. Sub-two nanometer single crystal Au nanowires. Nano Lett. 2008, 8, 2041-2044.

[32] Wang, C.; Hou, Y. L.; Kim, J. M.; Sun, S. H. A general strategy for synthesizing $\mathrm{FePt}$ nanowires and nanorods. Angew. Chem. Int. Edit. 2007, 46, 6333-6335.

[33] Sun, S. H.; Murray, C. B.; Weller, D.; Folks, L.; Moser, A. Monodisperse FePt nanoparticles and ferromagnetic FePt nanocrystal superlattices. Science 2000, 287, 1989-1992.
[34] Markovic, N. M.; Sarraf, S. T.; Gasteiger, H. A.; Ross, P. N. Hydrogen electrochemistry on platinum low-index singlecrystal surfaces in alkaline solution. J. Chem. Soc. Faraday Trans. 1996, 92, 3719-3725.

[35] Lima, F. H. B.; Salgado, J. R. C.; Gonzalez, E. R.; Ticianelli, E. A. Electrocatalytic properties of $\mathrm{PtCo} / \mathrm{C}$ and $\mathrm{PtNi} / \mathrm{C}$ alloys for the oxygen reduction reaction in alkaline solution. J. Electrochem. Soc. 2007, 154, A369-A375.

[36] Wang, J. X.; Markovic, N. M.; Adzic, R. R. Kinetic analysis of oxygen reduction on $\operatorname{Pt}(111)$ in acid solutions: Intrinsic kinetic parameters and anion adsorption effects. J. Phys. Chem. B 2004, 108, 4127-4133.

[37] Obradovic, M. D.; Grgur, B. N.; Vracar, L. M. Adsorption of oxygen containing species and their effect on oxygen reduction on $\mathrm{Pt}_{3} \mathrm{Co}$ electrode. J. Electroanal. Chem. 2003, 548, 69-78.

[38] Mayrhofer, K. J. J.; Hartl, K.; Juhart, V.; Arenz, M. Degradation of carbon-supported Pt bimetallic nanoparticles by surface segregation. J. Am. Chem. Soc. 2009, 131, 16348-16349. 